\title{
CLEAR CELL HYDRADENOMA OF EAC. A RARE CASE REPORT
}

Ranjan Kumar Guru.

1. Senior Resident, Department Of ENT, VSS Medical College, Burla Sambalpur, Odisha.

\section{CORRESPONDING AUTHOR:}

Ranjan Kumar Guru,

Senior Resident,

Department of ENT,

VSS Medical College, Burla,

Sambalpur, Odisha, PIN - 768017.

E-mail: dr.rkguru@gmail.com

ABSTRACT: Clear cell hidradenoma is an uncommon, mostly benign, slowly growing \& a rare skin tumour of eccrine sweat gland origin. Malignant transformation of these lesions is very rare. In the present communication, a histologically benign clear cell hidradenoma having an aggressive clinical behavior with rapid growth \& pigmentation is described.

KEY WORDS: Clear cell hydradenoma; Eccrine gland tumour; Sweat gland tumour

INTRODUCTION: Clear cell hydradenoma is known by various other names such as nodular hidradenoma, eccrine acrospiroma, and solid-cystic hidradenoma.[4] This is a rare, benign, slowly growing cutaneous tumour of the sweat glands. During the course of years no single term has been universally accepted. The patients with $\mathrm{CCH}$ are usually in their fourth decade or older. The tumor grows slowly and can be present for several years without apparent change. It is mostly seen in adults and is characterized clinically by solitary and firm intradermal nodule. Histopathologically both solid and cystic portions are present with characteristic clear cells, which contain a large amount of glycogen and thus appear clear under light microscopy.[4,5] Presence of malignant change is suggested clinically by a rapid growth, pigmentation and cutaneous ulceration and histologically by an increased number of mitotic figures, nuclear atypia and angiolymphatic or perineural invasion.[1] Lesions having frequent mitoses or nuclear atypia but lacking clear evidence of asymmetric invasive growth are termed as atypical $\mathrm{CCH}$ and require an aggressive management in view of a risk of recurrence and malignant transformation.[4,5] We report a patient with large, pigmented $\mathrm{CCH}$ arising from EAC that clinically resembled a squamous cell carcinoma.

CASE REPORT: A $50 \mathrm{yr}$ aged Hindu female presented with fleshy growth protruding from left EAC since last 8 yrs [FIGURE-1]. To start with the rate of growth was slow \& the growth is rapid since last 8 months. She developed decrease hearing in left ear since last $7 \mathrm{yrs}$, which was progressive in nature \& since last 1year she is unable to hear in left ear. She has suffered from bleeding from left ear [6 - 7 episodes] in last 8 years. On examination a fleshy mass with pigmentation on surface, arising from left EAC $5 \times 4 \times 4 \mathrm{~cm}$, firm, non tender, insensitive to touch, does not bleed on touch, on probing it seems to arise from EAC of left ear [FIGURE -1]. There was no regional lymphadenopathy; general physical and systemic examination was normal. A clinical possibility of 


\section{CASE REPORT}

squamous cell carcinoma was considered. CT scan of temporal bone shows soft tissue mass involving left ext. auditory canal [EAC] \& extending upto middle ear without bone erosion [FIGURE$2]$.

An excisional biopsy by trans-canal approach was done. Histopathology [FIGURE-5] revealed a well circumscribed tumor in the dermis composed of variably sized tubular lumina and cystic spaces. In addition the tumor had numerous polyhedral and clear cells, whorl of squamous cells with eosinophilic cytoplasm \& mucinous cells without nuclear atypia or vascular invasion. The cells contain clear cytoplasm separated by thin vascular stroma. Upper epidermis shows multiple large rounded eosinophilic inclusions like structure predominantly in granular \& horny cell layers. These are consistent with the diagnosis of clear cell hydradenoma The patient was healthy \& doing well after the operation [FIGURE-5].

DISCUSSION: Incidence of Clear cell hidradenomas [CCH] is twice more common in females \& usually seen after 4th decade of life.[4] Clinically the tumor appears as asymptomatic, usually solitary, 0.5 to $1 \mathrm{~cm}$ sized, skin colored intradermal nodule, slightly elevated above the surrounding skin. $[4,5]$ Occasionally brown, blue or red discoloration and surface erosions or ulceration may be observed. It is a slow growing tumour and rapid growth may represent trauma, hemorrhage or a malignant change. $[3,5]$

Clinical differential diagnosis includes basal cell and squamous cell carcinoma, melanoma, metastatic tumor, dermatofibroma, pyogenic granulomas, hemangioma, leiomyoma and other cutaneous adnexal tumors.[4,5] Differentiation depends upon biopsy and immunohistochemical staining.[5] Histopathology shows both solid and cystic components in varying proportions. The tumor has tubular lumina lined by cuboidal or columnar cells and variably sized cystic spaces. The solid portions contain two types of cells: polyhedral cells with eosinophilic cytoplasm and glycogen containing pale or clear cells with a clear cytoplasm and a round nucleus. [4]

Criteria for assessing malignancy include overt nuclear atypia, readily observed mitotic figures, infiltrative patterns, lymphatic or perineural invasion and areas of necrosis. CCH is labeled as atypical when there is no evidence of invasive features but it has a high mitotic rate or nuclear atypia. The exact frequency of atypical $\mathrm{CCH}$ and their risk of transformation into malignant tumors are not known. However, mitotic activity and cellular pleomorphism may not be accurate predictors of clinical behaviour.

Malignant CCH usually arise de novo and malignant transformation of benign CCH has rarely been reported.[1] Biddlestone et al have described a young girl with progression of a histologically benign hidradenoma to a malignant sweat gland carcinoma with metastasis over a period of 11 years.[1] However, mitotic activity and cellular pleomorphism may not be accurate predictors of clinical behavior.[5] Clinically benign CCH with focal nuclear pleomorphism and increased mitotic activity have been reported, while tumors with aggressive clinical behavior and metastasis may have deceptively benign histological appearance.[1,3]

In the reported case, potential for aggressive behavior was suggested by the clinical findings of a rapid growth and pigmentation. However there were no features of nuclear atypia or angiolymphatic invasion and thus the lesion was histologically benign. The present case thus illustrates that an aggressive clinical behavior may not always parallel the histologic features. 


\section{CASE REPORT}

Treatment of benign, atypical and malignant $\mathrm{CCH}$ is surgical excision with adequate margins to minimize the risk of recurrence followed by histologic confirmation of adequacy of excision.[1,5] In view of reported malignant transformation, how so ever rare, even the histologically benign lesions should be promptly diagnosed followed by surgical excision and histologic confirmation of clearance.

\section{ABBREVIATIONS:}

1. EAC -external auditory canal

2. $\mathrm{CCH}$-clear cell hydradenoma

\section{REFERENCES:}

1. Biddlestone LR, Mc Laren KM, Tidman MJ: Malignant hidradenoma: a case report demonstrating insidious histological and clinical progression. Clin Exp. Dermatol, 1991; 16:474-477.

2. Gianotti R, Alessi E: Clear cell hidradenoma associated with the folliculose baceous apderine unit. Am J Dermatopathol, 1997; 19:351-357.

3. Dumont K, Humph rays T, Malhotra R: Stump the experts. Dermatol Rev.1996; 22:998-999..

4. Elder D, Elentisas R, Ragsdale BD: Tumors of the epidermal appendages, in David E (ed): Lever's Histopathology of the Skin, Philadelphia: Lippincott- Raven Publishers, 1997, p 747804.

5. Wilhelmi BJ, Appelt EA, Philips LG: A rare case of atypical eccrine acrospiroma of the scalp and a literature review, Ann Plast Surg, 1999; 42: 568-569.

6. IADVL: Text book of Dermatology 3rd ed, by R.G. Valia \& Ameet R. Valia. 


\section{CASE REPORT}

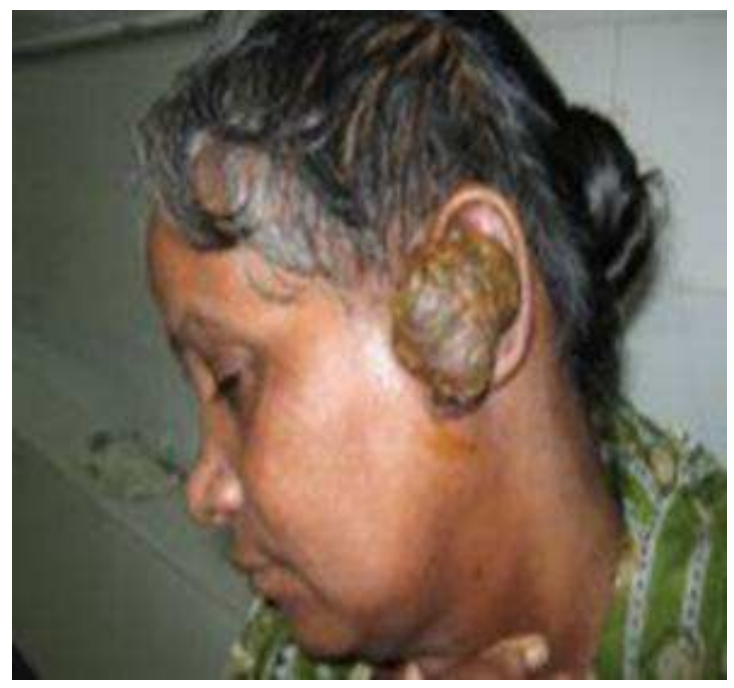

Figure1: Pre-operative photo showing mass arising from ear with pigmentation

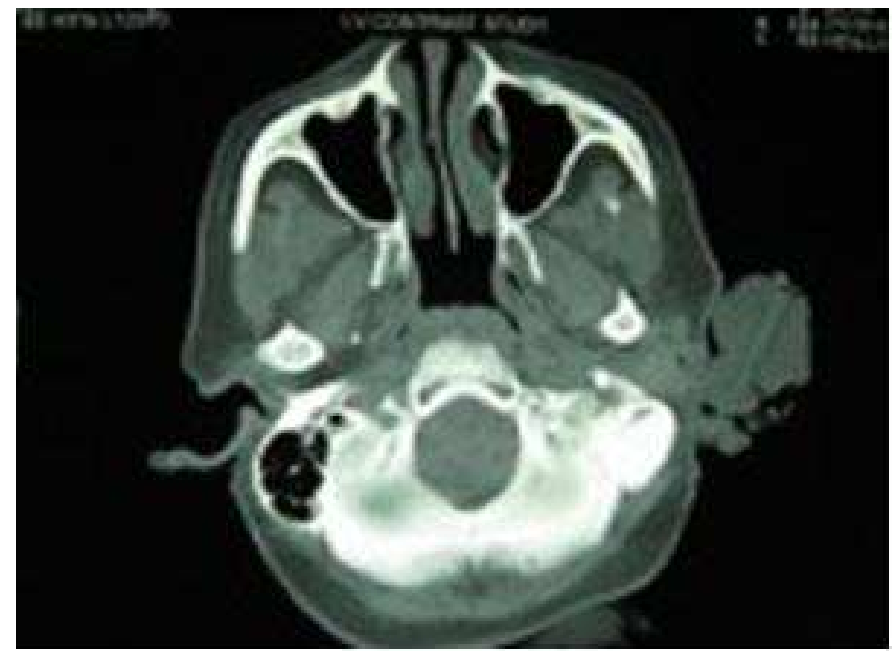

Figure 2: CT scan axial view showing mass arising from ear \& extending upto middle ear

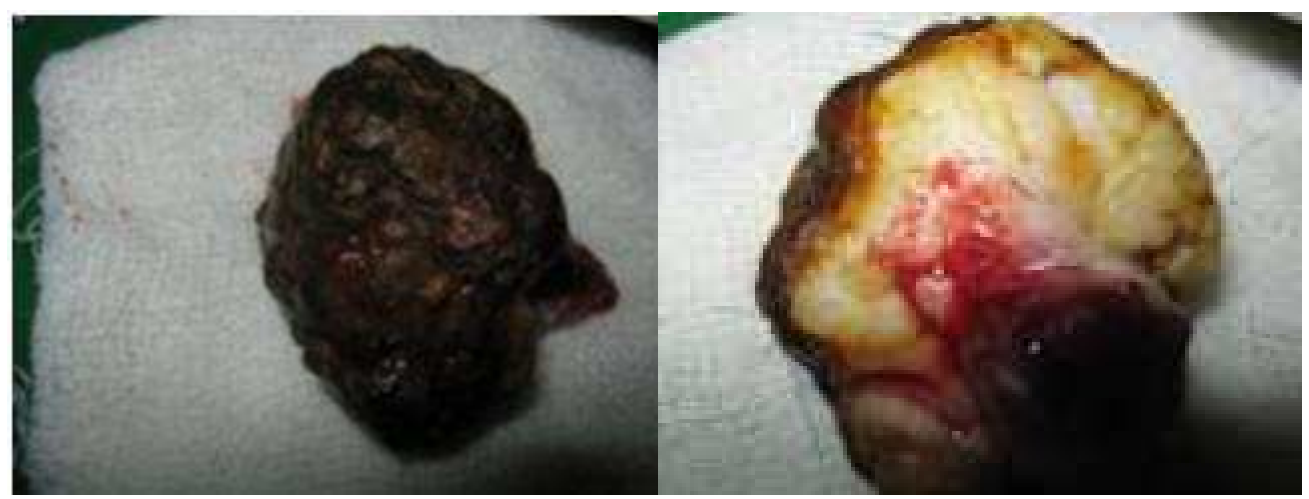

Figure 3: mass after removal 


\section{CASE REPORT}

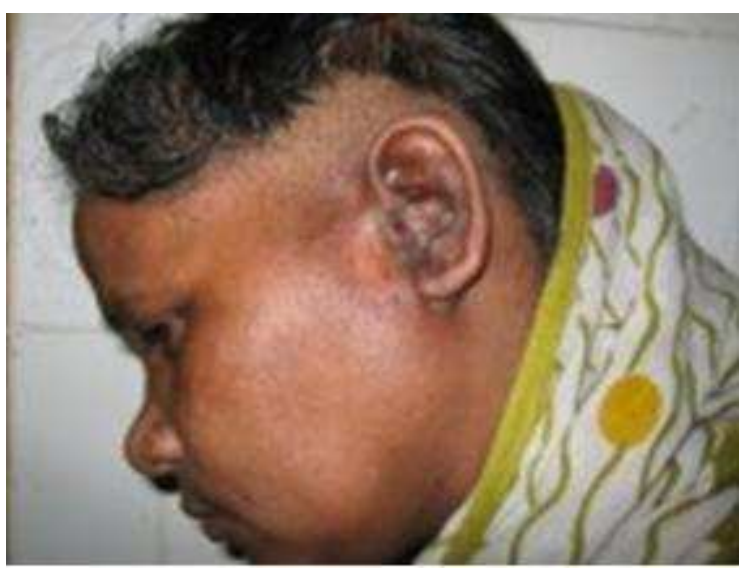

Figure 4: 5 days post operative

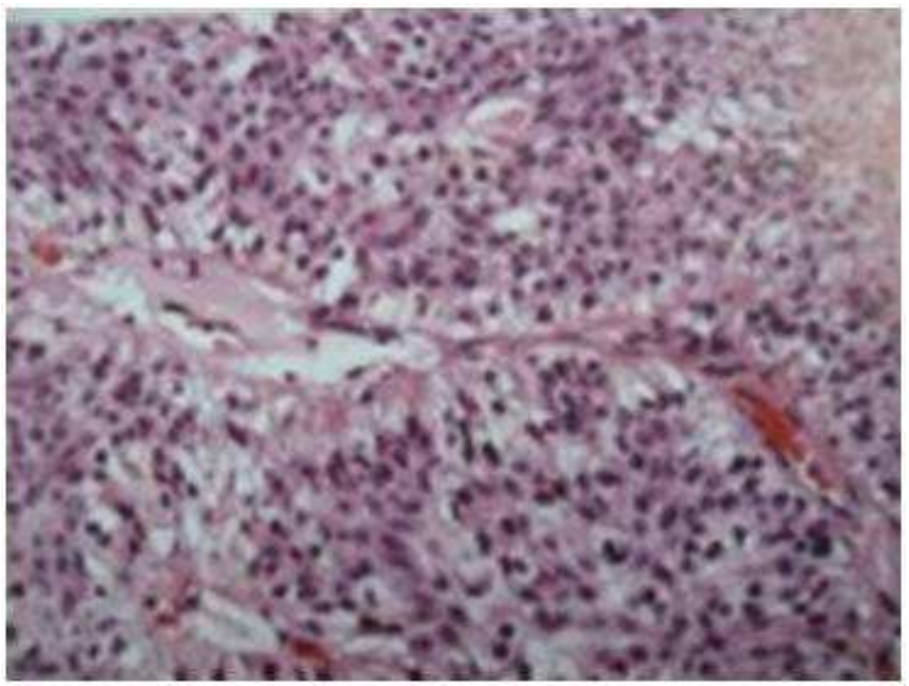

Figure 5: histopathology showing clear cells \& whorl of squamoid cells with eosinophilic cytoplasm 